\title{
HERITABILITY AND C EFFECTS IN EARLY ROOT GROWTH OF EASTERN COTTONWOOD CUTTINGS
}

\author{
JAMES R. WILCOX* and ROBERT E. FARMER, Jr. $\dagger$ \\ Southern Forest Experiment Station, Forest Service, \\ U.S. Department of Agriculture
}

Received 24.vii.67

\section{INTRODUCTION}

Commercial plantations of eastern cottonwood (Populus deltoides Bartr.) in the lower Mississippi Valley are commonly established with unrooted stem cuttings (Maisenhelder, 1960). In genetic improvement work, replicated clonal tests are conducted to estimate heritability of various characters and to evaluate the genetic potential of the clones. Differences among clones in rapidity of initial root development could affect establishment and evaluations of early growth. These clonal differences may either be inherent or due to $\mathrm{G}$ effects (Lerner, 1958), i.e. physiological or morphological characteristics unique to the ortet because of its specific environment. In the present study, genetic variation and $\mathrm{C}$ effects for early root development and growth of eastern cottonwood were estimated.

\section{Methods}

In February 1963, 49 seedlings were selected at random in a 2-year-old natural stand of cottonwood in Bolivar County, Mississippi. Six 51-cm. cuttings (primary ramets) were made from each selection. They were immediately field-planted at a $3.7 \times 3.7 \mathrm{~m}$. spacing in a randomised block design with six replications. From each clone, the cutting of smallest diameter was assigned to one replication, and progressively larger cuttings to the succeeding replications. Thus, cutting diameter was completely confounded with replications. This plantation was the source of material for two experiments.

\section{Experiment I}

The inheritance of rooting in two media was studied in the 49 clones. In March 1964, two 15-cm. cuttings (secondary ramets) were taken from the tips of lateral branches of each primary ramet in four of the field replications. Eight cuttings of each clone (two from each primary ramet) were planted to a $13-\mathrm{cm}$. depth in individual $1.9 \mathrm{l}$. containers. Half the cuttings were planted in Sharkey clay, a poorly drained soil with a montmorillonite clay content of 74-85 per cent., and half in a standard potting mixture of 1 part sand, 1 part fine peat, and 2 parts loam. Sharkey clay is the soil on the 1963 planting site; the potting mixture was a convenient and contrasting test medium.

* Formerly of the Institute of Forest Genetics, Gulfport, Mississippi. Now with the Agricultural Research Service, U.S. Department of Agriculture, Purdue University, Lafayette, Indiana.

$\uparrow$ Southern Hardwoods Laboratory, which is maintained at Stoneville, Mississippi, by the Southern Forest Experiment Station in cooperation with the Mississippi Agriculture Experiment Station and the Southern Hardwood Forest Research Group. 
The potted cuttings were arranged in a split-plot design of four replications in a lathhouse at Stoneville, Mississippi. Soil types were the main plots and clones the subplots. The containers were watered as required to maintain soil moisture at field capacity.

Date of leaf emergence was recorded for each plant. The rooted cuttings in two replications were carefully washed from the soil on 6th and 7th April 1964. Since roots had not developed as rapidly as anticipated, the cuttings in the remaining two replications were not washed out until 16th and 17 th April. Number of roots, total length of primary roots to the nearest millimetre, and dry weight of roots to the nearest milligram were recorded for each cutting. Prior to analyses, all root measurements were transformed to $\log _{10}(X+1)$ because clone variances tended to increase with clone means. Data on number of roots were analysed by a split-split-plot method with two replications. Lifting dates were the main plots, soil types the subplots, and clones the sub-subplots. None of the interactions involving date of lifting was significant $(0.05$ level $)$, and other root measurements were highly correlated with number of roots $(r=0 \cdot 94-1 \cdot 00)$. Computations of heritability for all characters were therefore based on four replications with lifting date ignored. " $F$ " tests were conducted at the 0.05 level of probability.

\section{Experiment II}

To test for $\mathrm{C}$ effects, the average variation among primary ramets within clones was compared with that within primary ramets (among secondary ramets). Ten clones were selected to represent the range in variability for rooting characteristics determined in Experiment I. In February 1966, four 15-cm. terminal branch cuttings (secondary ramets) were collected from each of four primary ramets of the clones. Cuttings were planted as before in a standard potting mixture, and containers were arranged in a completely randomised design in the lath-house. Foliation date was recorded for each cutting and the cuttings were washed free of soil on 25th April 1966. Number of primary roots and dry weight of roots and shoots in milligrams were recorded. Data on roots were transformed as in the first experiment.

\section{REsULts}

\section{Experiment I}

The differences among clones for the three root measurements were statistically significant and large. Some clones had well-developed root systems when the test was dismantled while a few were just beginning to root (table 1).

Mean root number and root length in the two soils were not significantly different. Dry weight of roots was significantly greater, and flushing date later, in the potting mixture than in the Sharkey clay.

The interactions of the clones with soil type were highly significant for the characters studied. Some clones developed roots fastest in Sharkey clay, others did better in the potting mixture.

Because clones differed in root weight and flushing date in the two soils, a separate analysis of variance was computed for each character in each soil. The magnitude of the variation among clones was compared by separating out both the clone and error components of variance for the four 
characters in each soil. Heritabilities based on these components are included in table 1 .

The genetic component of variance was smaller than the environmental component for each of the root characters in the potting soil. In Sharkey clay the genetic component was larger than the environmental component, and was also larger than the genetic component in the potting soil. Thus, in clay, heritabilities were relatively high and essentially the same $(0.52$ to 0.58 ) for the three rooting parameters. In the potting soil, the heritabilities were slightly lower. They ranged from 0.33 for root length to 0.44 for number of roots. Heritabilities for foliation date in the rooting phase of

TABLE 1

Means, ranges, estimated environmertal and genetic variances, and heritabilities for three root measurements and fushing date of 49 eastern cottonwood clones (Experiment I)

\begin{tabular}{|c|c|c|c|c|c|}
\hline Character & Mean & $\begin{array}{l}\text { Range of } \\
\text { clone means }\end{array}$ & $\begin{array}{c}\text { Genetic } \\
\text { variance } \\
\sigma_{G}^{2}\end{array}$ & $\begin{array}{c}\text { Environmental } \\
\text { variance } \\
\sigma_{\mathrm{E}}^{2}\end{array}$ & $\begin{array}{c}\text { Heritability } \\
\frac{\sigma_{\mathrm{G}}^{2}}{\sigma_{\mathrm{G}}^{2}+\sigma_{\mathrm{E}}^{2}}\end{array}$ \\
\hline \multicolumn{6}{|l|}{ Number of roots } \\
\hline $\begin{array}{l}\text { Potting soil } \\
\text { Sharkey clay }\end{array}$ & $\begin{array}{l}2 \cdot 7 \\
3 \cdot 4\end{array}$ & $\begin{array}{l}0 \cdot 4-8 \cdot 3 \\
0 \cdot 2-23 \cdot 0\end{array}$ & $\begin{array}{l}0.0347 \\
0.0868\end{array}$ & $\begin{array}{l}0.0448 \\
0.0676\end{array}$ & $\begin{array}{l}0.44 \\
0.56\end{array}$ \\
\hline Combined & $3 \cdot 0$ & $0 \cdot 3-13 \cdot 9$ & - & - & - \\
\hline \multicolumn{6}{|l|}{ Root length $(\mathrm{cm})}$. \\
\hline $\begin{array}{l}\text { Potting soil } \\
\text { Sharkey clay } \\
\text { Combined }\end{array}$ & $\begin{array}{l}7 \cdot 6 \\
4 \cdot 1 \\
5 \cdot 6\end{array}$ & $\begin{array}{l}3 \cdot 6-48 \cdot 8 \\
0 \cdot 1-102 \cdot 3 \\
0 \cdot 3-70 \cdot 7\end{array}$ & $\begin{array}{l}0.2331 \\
0 \cdot 3669 \\
-\end{array}$ & $\begin{array}{l}0.4704 \\
0.3339 \\
-\end{array}$ & $\begin{array}{l}0.33 \\
0.52 \\
-\end{array}$ \\
\hline \multicolumn{6}{|l|}{ Root weight (mg.) } \\
\hline $\begin{array}{l}\text { Potting soil } \\
\text { Sharkey clay } \\
\text { Combined }\end{array}$ & $\begin{array}{l}9 \cdot 9 \\
3 \cdot 0 \\
5 \cdot 6\end{array}$ & $\begin{array}{l}0 \cdot 9-46 \cdot 3 \\
0 \cdot 0-26 \cdot 8 \\
0 \cdot 5-26 \cdot 9\end{array}$ & $\begin{array}{l}0.0842 \\
0 \cdot 1187 \\
-\end{array}$ & $\begin{array}{l}0 \cdot 1496 \\
0 \cdot 0851 \\
\cdots\end{array}$ & $\begin{array}{c}0.36 \\
0.58 \\
-\end{array}$ \\
\hline \multicolumn{6}{|c|}{ Foliation date (days after 28th February 1964) } \\
\hline $\begin{array}{l}\text { Potting soil } \\
\text { Sharkey clay } \\
\text { Combined }\end{array}$ & $\begin{array}{l}34 \\
30 \\
32\end{array}$ & $\begin{array}{l}18-50 \\
18-49 \\
19-49\end{array}$ & $\begin{array}{r}28 \cdot 50 \\
48 \cdot 38 \\
-\end{array}$ & $\begin{array}{r}2 \cdot 87 \\
16 \cdot 12 \\
-\end{array}$ & $\begin{array}{l}0.91 \\
0.75 \\
-\end{array}$ \\
\hline
\end{tabular}

the study are of the same magnitude as those for the 1963 field planting (0.99) (Wilcox and Farmer, 1967) and are considerably higher than values for root characters.

Phenotypic and genotypic correlation coefficients, computed among the three root determinations, ranged from 0.94 to 1.00 (significant at 0.05 level). A significant negative correlation $(-0 \cdot 68)$ was obtained between root weight and flushing date. This suggests that clones which flushed early also started root growth early, and thus, developed the heaviest roots during the study. None of the root measurements in either soil was significantly correlated with early height growth in the 1963 field planting.

Distribution of roots along the cuttings differed in the two soils (plate). In Sharkey clay, roots developed prolifically near the surface of the soil and decreased in frequency with increasing soil depth. In the potting soil the roots were largely restricted to the base of the cutting. This probably was a reflection of poorer aeration in Sharkey clay. 


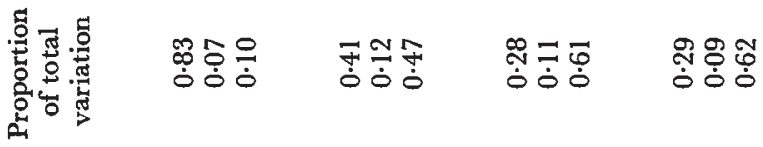

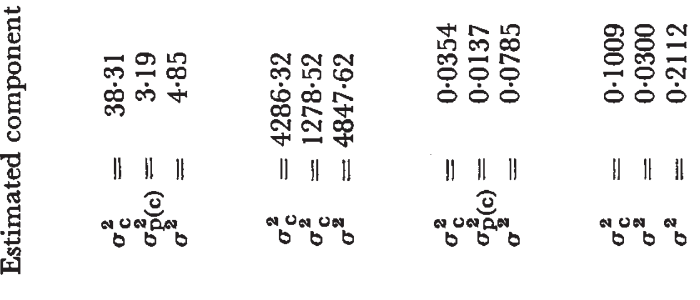
证

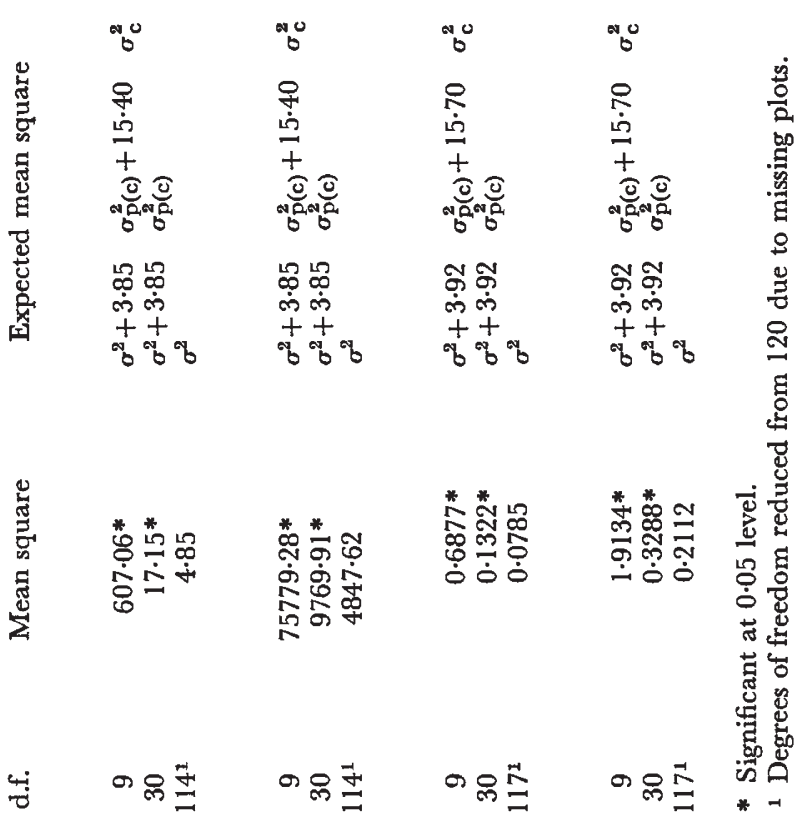
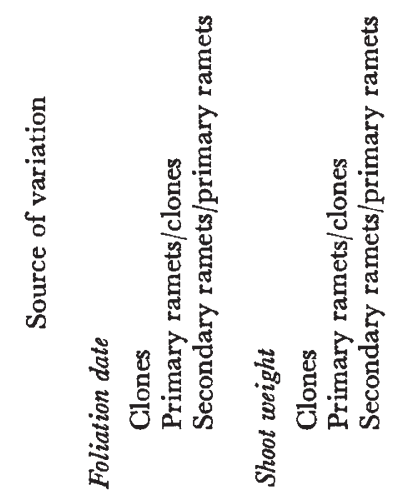

总

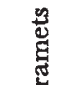

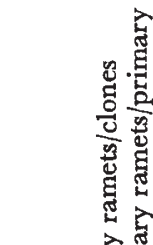




\section{Experiment II}

As in the first experiment, differences among clones were significant for each of the characteristics evaluated (table 2). The smallest though statistically significant variance component was for primary ramets within clones ( $\mathrm{C}$ effects). Components due to secondary ramets were larger than the clone components for all characteristics except foliation date. For this character the clone component was predominant.

TABLE 3

The range in primary ramet means and the clone means for four characteristics of eastern cottonwood (Experiment II)

$\begin{array}{ccccc}\text { Clone } & \begin{array}{c}\text { Foliation } \\ \text { date }\end{array} & \begin{array}{c}\text { Shoot } \\ \text { weight } \\ \text { mg. }\end{array} & \begin{array}{c}\text { Root } \\ \text { number }\end{array} & \begin{array}{c}\text { Root weight } \\ \text { mg. }\end{array} \\ 1 & 3 / 31-4 / 5 * & 168-312^{*} & 1-6 * & 6-43^{*} \\ & 4 / 2 & 265 & 3 & 13 \\ 5 & 4 / 7-4 / 10 & 86-193 * & 9-11 & 23-49 \\ & 4 / 9 & 154 & 10 & 39 \\ 15 & 4 / 11-4 / 13 & 120-185 & 5-13 & 10-21 \\ & 4 / 12 & 151 & 7 & 16 \\ 21 & 3 / 20-3 / 22 & 261-434 * & 5-10 & 55-114 \\ & 3 / 21 & 368 & 8 & 80 \\ 23 & 4 / 5-4 / 9 * & 102-133 & 1-3 & 2-8 \\ & 4 / 7 & 123 & 2 & 4 \\ 26 & 4 / 3-4 / 6 & 172-248 & 6-15 & 41-64 \\ & 4 / 4 & 203 & 10 & 46 \\ 30 & 3 / 23-4 / 3 * & 133-199 & 0-5 * & 1-73 * \\ & 3 / 28 & 174 & 3 & 12 \\ 34 & 4 / 2-4 / 3 & 174-248 & 3-5 & 19-47 \\ & 4 / 2 & 213 & 4 & 32 \\ 47 & 3 / 29-4 / 1 & 184-298 * & 2-7 & 11-41 \\ & 3 / 30 & 243 & 4 & 22 \\ 48 & 3 / 29-4 / 3 * & 112-258 * & 1-8 * & 9-54 * \\ & 4 / 1 & 188 & 4 & 25\end{array}$

* Primary ramet means differed significantly at the 0.05 level.

Primary ramets differed significantly, according to Duncan's multiple range test (1955), in four clones for foliation date, five clones for shoot weight, and three clones for both number of primary roots and root weight (table 3 ). In only two of the ten clones, 1 and 48, were differences among primary ramets significant for all four characteristics.

\section{Discussion and conclusions}

The data demonstrate that variation in early root development of cottonwood clones is under fairly strong genetic control and therefore responsive to selection. This variation is strongly related to highly heritable clone differences in foliation date. The high correlations among root characteristics in Experiment I indicate that the three root measurements would be equally useful in evaluating rooting ability of the clones.

Clonal differences in root characteristics have been reported for Norway spruce (Deuber, 1940; Mergen, 1960), red maple (Snow, 1939), sugar maple (Dunn and Townsend, 1954), and several Populus species (Bloomberg, 1959, 1963). Only Mergen (1960) estimated the genetic control of clonal differences in root characters. He calculated a broad-sense heritability on 
an individual plant basis of 0.69 for root volume (root number $\times$ length) of Norway spruce cuttings collected from dormant trees.

The presence of $\mathrm{C}$ effects in the present study, estimated from primary ramets, might cause considerable bias in estimating heritabilities and subsequent gains from selection. Assume the proportion of total variation (table 2) among clones is an accurate measurement of genetic differences and that among secondary ramets an accurate estimate of environmental effects. Broad-sense heritability estimates for the four characters would then be: foliation date $0 \cdot 89$, shoot weight $0 \cdot 47$, root number 0.31 , and root weight $0 \cdot 32$. If secondary cloning had not been employed, the variation attributable to primary ramets ( $\mathrm{C}$ effects) would have been associated with clonal variation and, as a result, heritabilities of the four characters would have been over-estimated as $0.90,0.53,0.39$ and 0.38 . In contrast, even with secondary cloning, if primary ramet effects had been ignored in the analyses, the variation attributable to primary ramets would have been associated with environment. Hence, broad-sense heritabilities would have been underestimated as $0.83,0.41,0.28$, and 0.29 for the characters.

Libby and Jund (1962) have suggested reducing G effects by two-stage cloning. They recommend growing ramets in randomly assigned positions in the non-uniform experimental environment, then, after the ramets have responded to these environments, re-cloning to form an experimental population. In the present study, ramets were re-cloned after growing for three years on a uniform field site, and apparently the primary ramets of some clones had already responded to different micro-environments encountered. How long the effects will persist is unknown, but evidence from other studies suggests that they will disappear soon. In central Mississippi we found that the effects of cutting diameter on height growth of cottonwood were statistically significant only through August of the first season's growth. Libby and Jund (1962) reported diminishing amounts of $\mathrm{C}$ effects for characters expressed progressively later in the development of Mimulus guttatus clones.

In short-term clonal tests with cottonwood, $\mathrm{C}$ effects should be either minimised or controlled. Using cuttings of uniform age and size is one possibility. Two-stage cloning is another. Cuttings from primary ramets could be assigned to different replications in an experiment, or primary ramet effects could be estimated in analyses to give some statistical control to differences among the ramets.

\section{Summary}

1. Early root development on dormant cottonwood cuttings from 49 clones had a broad-sense heritability of $0 \cdot 33-0.44$ in a loam potting soil and 0.52-0.58 in Sharkey clay.

2. Clonal variation in rooting was strongly related to highly heritable differences in foliation date.

3. $\mathrm{G}$ effects, estimated by two-stage cloning, were large enough to be important in short-term clonal tests.

\section{REFERENCES}

BLOOMBERG, W. J. 1959. Root formation of black cottonwood cuttings in relation to region of parent shoot. For. Chron., 35, 13-17. 


\section{Plate}

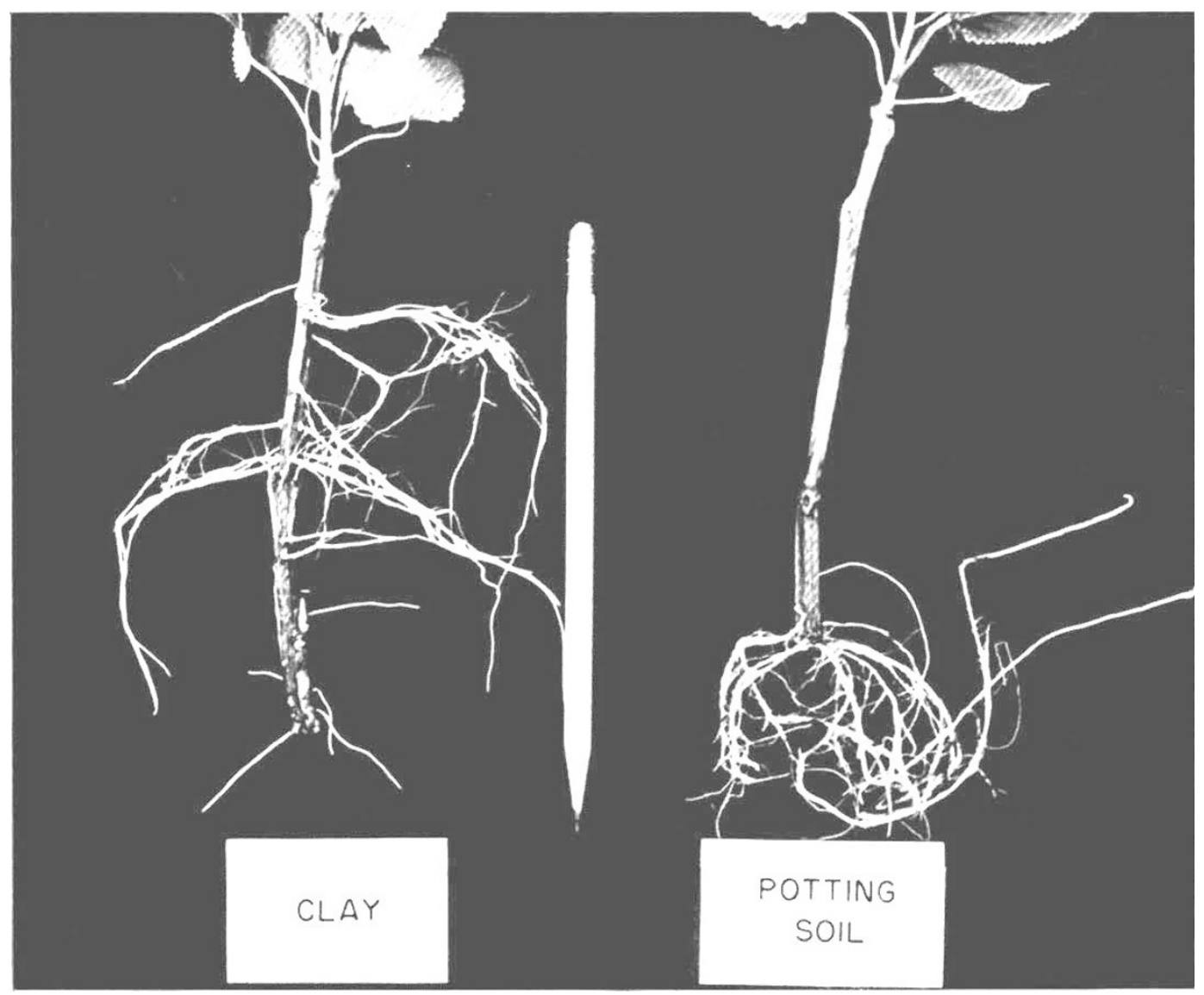

Rooting of two ramets of a single clone in the two soils. 
BLOOMBERG, w. J. 1963. The significance of initial adventitious roots in poplar cuttings and the effect of certain factors on their development. For. Chron., 39, 279-289.

DEUber, c. G. 1940. Vegetative propagation of conifers. Trans. Conn. Acad. Arts and Sci., $34,1-83$.

DUNCAN, D. B. 1955. Multiple range and multiple F tests. Biometrics, 11, 1-42.

DUNN, s., AND TOWNSEND, R. J. 1954. Propagation of sugar maple by vegetative cuttings. F. For., 52, 678-679.

LERnER, I. M. 1958. The Genetic Basis of Selection. John Wiley \& Sons, Inc., New York.

LIBBY, W. J., AND JUND, E. 1962. Variance associated with cloning. Heredity, 17, 533-540. MAISENHELDER, L. C. 1960. Cottonwood plantations for southern bottom lands. U.S. For. Serv., Sth. For. Exp. Sta. Occas. Pap. 179, New Orleans, La.

MERGEN, F. 1960. Variation and heritability of physiological and morphological traits in Norway spruce. Fifth World For. Cong. Proc. 1960, 755-757.

sNow, A. G., JR. 1939. Clonal variation in rooting response of red maple cuttings. U.S. For. Serv., Ntheast. For. Exp. Sta. Tech. Note 29, Upper Darby, Pa.

wILCOX, J. R., AND FARMER, R. E., JR. 1967. Variation and inheritance of juvenile characters of eastern cottonwood. Silvae Genet., 16, 162-165. 